\title{
EVALUASI IMPLEMENTASI PEMBELAJARAN KETERAMPILAN TUNE UP SEPEDA MOTOR PADA SISWA SEKOLAH MENENGAH KEJURUAN
}

\author{
Indra Kustiawan $^{1}$, Wahid Munawar ${ }^{2}$, Sriyono $^{3}$ \\ Departemen Pendidikan Teknik Mesin \\ Universitas Pendidikan Indonesia \\ Jl. Dr. Setiabudhi No. 207 Bandung 40154 \\ indra.kustiawan@ymail.com
}

\begin{abstract}
ABSTRAK
Tujuan penelitian ini mengevaluasi pembelajaran keterampilan tune up sepeda motor pada siswa SMK Negeri Sukaresik. Metode penelitian yang digunakan dalam penelitian ini adalah metode evaluasi dengan desain penelitian single subject research dimana terdapat proses pembelajaran keterampilan tune up sepeda motor, hasilnya diobservasi. Sampel dalam penelitian ini terdiri dari enam orang peserta didik kelas XII TSM SMK Negeri Sukaresik. Pemilihan sampel penelitian didasarkan pada pertimbangan dari guru mata pelajaran di sekolah tempat penelitian dan nilai peserta didik. Hasil penelitian ini: rata-rata waktu pengerjaan perawatan sepeda motor dari semua siswa adalah 121,58 menit dan persentase ketercapaian waktu pengerjaan untuk siswa dengan nilai tertinggi adalah $32 \%$ dan $20 \%$, nilai sedang masing-masing $14 \%$ dan siswa dengan nilai rendah mashing-masing 9\%. Waktu pengerjaan tune up sepeda motor yang dicapai oleh setiap siswa dijabarkan sebagai berikut: siswa dengan nilai tertinggi adalah 105 dan 116,5 menit, waktu pengerjaan siswa dengan nilai sedang adalah 119,5 dan 121,5 menit, sedangkan waktu pengerjaan untuk siswa dengan nilai terendah adalah 132,5 dan 134,5. Alokasi standar waktu untuk pengerjaan tune up adalah 90 menit. Dilihat dari data yang didapat tidak ada satupun siswa yang memenuhi standar untuk waktu pengerjaan tune up sepeda motor. rata-rata pencapaian hasil pengerjaan tune up sepeda motor dari semua siswa adalah 142. Ketercapaian hasil pengerjaan tune up sepeda motor oleh siswa dengan nilai tertinggi adalah $92.12 \%$ dan $91.52 \%$, siswa dengan nilai sedang $86.06 \%$ dan $87.88 \%$, sedangkan siswa dengan nilai terendah adalah $81.21 \%$ dan $78.18 \%$. Perincian pencapaian hasil kerja oleh setiap siswa adalah sebagai berikut: untuk siswa dengan nilai tertinggi mencapai 152 dan 151, siswa dengan nilai sedang 142 dan 145, sedangkan siswa dengan nilai rendah 134 dan 129. Pencapaian standar ketercapaian hasil tune up sepeda motor yang ditetapkan adalah 165. Dilihat dari data yang didapat tidak ada satupun siswa yang memenuhi standar untuk hasil pengerjaan tune up sepeda motor.
\end{abstract}

Kata kunci: evaluasi, tune up, single subject research, standar

\section{PENDAHULUAN}

Pendidikan di Indonesia merupakan salah satu sektor yang menjadi tujuan nasional. Tujuan Nasional ini tersurat dalam pembukaan Undang-Undang Dasar 1945 yaitu untuk mencerdaskan kehiduapan bangsa. Selain itu dalam pasal 31 ayat 1 UUD 1945 disebutkan bahwa setiap warga negara berhak mendapatkan pendidikan. Maka jelas bahwa penyelenggaraan pendidikan sangatlah penting demi terciptanya Sumber Daya Manusia (SDM) Indonesia yang berkualitas. Pendidikan nasional berfungsi mengembangkan kemampuan dan membentuk watak serta peradaban bangsa yang

\footnotetext{
${ }^{1}$ Mahasiswa Departemen Pendidikan Teknik Mesin FPTK UPI

2 Dosen Departemen Pendidikan Teknik Mesin FPTK UPI

${ }^{3}$ Dosen Departemen Pendidikan Teknik Mesin FPTK UPI
} 
bermartabat dalam rangka mencerdaskan kehidupan bangsa, bertujuan untuk berkembangnya potensi siswa agar menjadi manusia yang beriman dan bertakwa kepada Tuhan Yang Maha Esa, berakhlak mulia, sehat, berilmu, cakap, kreatif, mandiri, dan menjadi warga negara yang demokratis serta bertanggung jawab (Depdikbud, 2013).

Pelaksanaan proses pendidikan harus merata untuk seluruh warga negara Indonesia pada semua jenjang. Demikian pula dengan jenjang Sekolah Menengah Kejuruan (SMK). SMK merupakan salah satu penghasil SDM berkompeten yang diharapkan untuk siap bekerja di lingkungan masyarakat. Tujuan dari SMK itu sendiri yaitu untuk menyiapkan tenaga kerja untuk mengisi kebutuhan dunia usaha dan industri. Tujuan dari SMK ini dijelaskan dalam PP Nomor 29 Tahun 1990 tentang pendidikan menengah pasal 3 ayat 2 disebutkan bahwa pendidikan menengah kejuruan mengutamakan penyiapan siswa untuk memasuki lapangan kerja serta mengembangkan sikap profesional. Upaya peningkatan SDM ini diwujudkan dengan penyusunan kompetensi mata pelajaran yang nantinya akan mendukung terhadap kualitas dari kompetensi lulusan SMK itu sendiri.

Lulusan SMK banyak dibutuhkan di industri kendaraan sepeda motor yang bergerak dibidang jasa mengingat setiap tahunnya jumlah kendaraan semakin meningkat. Data Korps Lalu Lintas Kepolisian Negara Republik Indonesia mencatat, jumlah kendaraan sepeda motor yang masih beroperasi di seluruh Indonesia pada 2013 mencapai 104,211 juta unit, naik 11 persen dari tahun sebelumnya (2012) yang cuma 94,299 juta unit. Perkembangan sepeda motor yang pesat ini mendorong kebutuhan akan tune up terus meningkat. Imbas dari peningkatan kebutuhan akan tune up sepeda motor, maka tenaga kerja yang berkompeten untuk dunia industri sepeda motor pun menjadi lebih banyak. Persoalan yang terjadi ialah kualitas dari tenaga kerja dari lulusan SMK banyak yang tidak memenuhi kualifikasi pihak industri. Kendala ini terjadi karena beberapa faktor salah satunya akibat dari proses pembelajaran yang kurang mendukung.

SMK Negeri Sukaresik menerapkan keterampilan tune up sepada motor, namun berdasarkan observasi di SMK tersebut pelaksanaannya masih belum optimal. Fakta menunjukkan bahwa hasil tes uji kompetensi XII TSM sebagian besar masih rendah. Hal tersebut dapat dilihat dari daftar nilai ulangan harian (lampiran $5 \mathrm{hlm}$. 66), yaitu sebanyak 55\% siswa tergolong kategori belum tuntas, sedangkan 45\% siswa yang mampu melewati nilai sesuai dengan Kriteria Ketuntasan Minimal (KKM 75). Rendahnya hasil pembelajaran keterampilan tune up sepeda motor dapat dipengaruhi 
oleh berbagai faktor. Seperti kesulitan siswa dalam memahami pelajaran keterampilan tune up sepeda motor, penggunaan media belajar, cara guru mengajar keterampilan tune up sepeda motor dan sebagainya. Menurut salah satu guru di SMK Negeri Sukaresik mengemukakan beberapa faktor penyebab peserta didik kurang menguasai keterampilan tune up sepeda motor: (1) Kurangnya alat praktik otomotif sehingga membuat peserta didik susah berlatih; (2) Belum adanya standar evaluasi yang sesuai dengan kebutuhan industri; (3) Terbatasnya guru yang memiliki keterampilan teknik otomotif, yang dibutuhkan dalam melaksanakan kegiatan pembelajaran keterampilan; (4) Pemilihan metode yang kurang tepat digunakan pada mata pelajaran keterampilan (Nugraha, 2005).

Metode yang banyak diterapkan pada mata pelajaran keterampilan tune up sepeda motor adalah metode konvensional. Sehingga membuat peserta didik kurang paham dalam memahami materi yang disampaikan. Akibat dari kurang tepatnya metode yang digunakan, peserta didik di SMKN Sukaresik menjadi kurang terampil pada bidang keterampilan tune up sepeda motor. Faktor-faktor yang mempengaruhi belajar: faktor internal, yang meliputi keadaan jasmani dan rokhani siswa, faktor eksternal yang merupakan kondisi lingkungan di sekitar siswa. Faktor pendekatan belajar yang merupakan jenis upaya belajar siswa yang meliputi strategi dan metode yang digunakan siswa untuk melakukan kegiatan mempelajari materi-materi pelajaran (Syah, 2003).

Penelitian ini difokuskan terhadap pendekatan belajar yang di dalamnya terdapat metode yang digunakan dalam pembelajaran. Metode belajar yang digunakan akan mempengaruhi terhadap hasil belajar. Ketepatan (efektifitas) penggunaan metode pembelajaran tergantung pada kesesuaian metode pembelajaran dengan beberapa faktor, yaitu tujuan pembelajaran, materi pembelajaran, kemampuan guru, kondisi siswa, sumber atau fasilitas, situasi kondisi dan waktu (Sumiati dan Asra, 2011).

Penggunaan metode pembelajaran harus sesuai dengan tujuan pembelajaran, materi pembelajaran, kemampuan guru, kondisi peserta didik, sumber atau fasilitas, situasi kondisi dan waktu. Tidak memperoleh gambaran nyata menjadi kendala untuk anak SMK dalam proses pembelajaran keterampilan tune up sepeda motor. Prinsipnya dalam pembelajaran keterampilan otomotif, akan lebih efektif apabila siswa dibimbing dan langsung melihat pada benda aslinya. Berdasarkan pendapat Sumiati dan Asra, penulis berpendapat bahwa metode demontrasi merupakan metode yang dipandang relevan dan tepat untuk proses pembelajaran keterampilan bagi siswa SMK. 
Setelah melalui proses pembelajaran sudah seharusnya diadakan sebuah evaluasi agar kita mengetahui apakah pembelajaran yang sudah kita lakukan berhasil atau tidak. Proses evaluasi itu sendiri terdiri dari mengukur dan menilai. Pembelajaran keterampilan tune up sepeda motor ini diukur melalui indikator-indikator yang telah disusun berdasarkan pengalaman dan standar operasional prosedur dari buku manual motor Honda supra tahun 2002 dan sumber lainnya. Sedangkan penilaiannya diambil dari segi waktu kerja dan hasil kerja yang dicapai oleh siswa didik.

\section{METODE PENELITIAN}

Metode penelitian adalah penelitian deskriptif evaluatif dengan pendekatan kuantitatif. Penelitian evaluatif merupakan suatu desain dan prosedur evaluasi dalam mengumpulkan dan menganalisis data secara sistematis. Ciri studi evaluatif adalah lebih diarahkan untuk pengambilan keputusan daripada pembuktian hipotesis, nilai dari suatu evaluasi terletak pada prosesnya, proses evaluasi lebih penting daripada produk, dan kesimpulan selalu dibuat berdasarkan informasi yang lengkap oleh karenanya evaluasi sungguh-sungguh dapat mengurangi ketidakpastian.

Model evaluasi yang digunakan yaitu model evaluasi Stake. Penekanan evaluasi pada dua jenis operasional, yaitu deskripsi dan pertimbangan serta membedakan tiga fase dalam evaluasi program yaitu persiapan, proses serta keluaran. Model ini dipilih karena peneliti ingin mengetahui pelaksanaan pembelajaran dari sudut perencanaan, pelaksanaan dan hasil pembelajaran sehingga sesuai dengan model Stake.

\section{HASIL PENELITIAN}

Pengujian instrument penelitian menggunakan Content Validity Rasio (CVR) dan Content Validity Index (CVI). Hasil pengujian pada instrumen pengerjaan perawatan motor Honda supra tahun 2002 memiliki nilali 0,96. Artinya nilai tersebut menunjukan bahwa instrumen yang disusun memiliki predikat sangat valid. Analisi hasil pengujian validitas penilaian kinerja perawatan sepeda motor Honda supra tahun 2002 selain menggunakan CVR, juga menggunakan CVI. Perhitungan nilai CVI diperoleh 0,92 (sangat valid). Perhitungan nilai CVI yang didapat, instrumen pengerjaan perawatan motor Honda supra tahun 2002 yang disusun dinyatakan sangat valid dan dapat digunakan karena memenuhi nilai CVI lebih dari 0,67. 
Guru menjelaskan alat-alat yang diperlukan untuk tune up sepeda motor serta fungsinya dengan cara mendemonstrasikan. Bentuk dari alat harus siswa kenali sesuai namanya, agar tidak terjadi kesalahan dalam melaksanakan tune up. Guru mendemonstrasikan langsung proses kerja tune up sepeda motor. Guru membantu siswa yang mengalami kesulitan dalam proses tune up sepeda motor dengan cara memegang alat, memposisikan alat, penggunaan alat sesuai fungsinya. Guru menyimpulkan materi dan menginformasikan materi selanjutnya. Siswa dan guru yang menilai hasilnya. Proses pengerjaan tune up oleh siswa. Kegiatan selama pengerjaan perawatan sepeda motor dihitung lama waktu pengerjaan pada setiap siswa.

Tabel 1. Waktu Pengerjaan Tune Up Sepeda Motor

\begin{tabular}{|c|c|c|c|c|c|c|c|c|}
\hline \multirow{2}{*}{ No } & \multirow{2}{*}{ Indikator } & \multicolumn{7}{|c|}{ Waktu (menit) } \\
\hline & & Std. & $\mathrm{S} 1$ & $\mathrm{~S} 2$ & S3 & $\mathrm{S} 4$ & S5 & S6 \\
\hline 1 & Persiapan Kerja & 4 & 4.5 & 5 & 6 & 5 & 6 & 6 \\
\hline 2 & Busi & 3 & 3 & 4 & 3 & 3 & 5 & 4 \\
\hline 3 & Renggang Klep & 21 & 25 & 28 & 30 & 30 & 31 & 32 \\
\hline 4 & Saringan Udara & 6 & 7 & 7.5 & 8 & 8 & 9 & 8 \\
\hline 5 & Saluran Bahan Bakar & 0.5 & 0.5 & 0.5 & 0.5 & 0.5 & 0.5 & 0.5 \\
\hline 6 & Saringan Kasa Bahan Bakar & 4 & 4 & 5 & 5 & 7 & 6 & 7 \\
\hline 7 & Saringan Bahan Bakar & 1 & 1 & 1 & 1 & 1 & 1 & 1 \\
\hline 8 & Putaran Statsioner Engine & 4 & 5 & 5 & 6 & 5 & 7 & 7 \\
\hline 9 & Cara Kerja Gas Tangan & 2 & 3 & 3 & 4 & 3 & 5 & 5 \\
\hline 10 & Oli Engine & 7 & 8 & 9 & 8 & 8 & 9 & 9 \\
\hline 11 & Kopling & 2.5 & 3 & 3 & 3 & 4 & 3 & 4 \\
\hline 12 & Rantai Roda & 9 & 10 & 11 & 10 & 12 & 12 & 11 \\
\hline 13 & Rem Depan/Belakang & 3 & 4 & 5 & 5 & 4 & 5 & 5 \\
\hline 14 & Seklar Lampu Rem & 1.5 & 2 & 3 & 3 & 2 & 2 & 3 \\
\hline 15 & $\begin{array}{l}\text { Tekanan Angin Ban dan } \\
\text { Kondisi Ban }\end{array}$ & 2.5 & 3 & 3 & 3 & 3 & 4 & 4 \\
\hline 16 & Suspensi & 1.5 & 2 & 2 & 2 & 2 & 3 & 2 \\
\hline 17 & Standar Samping & 0.5 & 0.5 & 0.5 & 1 & 1 & 1 & 1 \\
\hline 18 & Bantalan Peluru Kemudi & 0.5 & 0.5 & 1 & 1 & 1 & 1 & 1 \\
\hline 19 & Batere & 12 & 13 & 14 & 13 & 14 & 15 & 16 \\
\hline 20 & Arah Sinar Lampu Depan & 3 & 3 & 3 & 4 & 4 & 4 & 4 \\
\hline 21 & Lampu Sein & 0.5 & 1 & 1 & 1 & 1 & 1 & 1 \\
\hline \multirow[t]{3}{*}{22} & Klakson & 1 & 2 & 2 & 2 & 3 & 2 & 3 \\
\hline & Total Waktu Pengerjaan & 90 & 105 & 116.5 & 119.5 & 121.5 & 132.5 & 134.5 \\
\hline & Jumlah Indikator & 22 & 7 & 4 & 3 & 3 & 2 & 2 \\
\hline
\end{tabular}


Rata-rata waktu untuk pengerjaan perawatan sepeda motor adalah 121,58 menit, total waktu dari keseluruhan yaitu 729,5 menit. Setiap siswa memiliki waktu penyelesaian yang berbeda-beda. Persentase pencapaian waktu standar (Tabel 1) oleh setiap siswa, dihitung dan diperoleh sebesar $32 \%$. Persentase pencapaian untuk semua siswa diperoleh seperti pada Tabel 2.

Tabel 2. Persentase Pencapaian Waktu Standar Siswa

\begin{tabular}{lccccccc}
\hline \multirow{2}{*}{\multicolumn{1}{c}{ Indikator }} & $\mathrm{7}$ & $\mathrm{S} 1$ & $\mathrm{~S} 2$ & $\mathrm{~S} 3$ & $\mathrm{~S} 4$ & $\mathrm{~S} 5$ & $\mathrm{~S} 6$ \\
\cline { 2 - 9 } & 22 & 7 & 4 & 3 & 3 & 2 & 2 \\
\hline Jumlah Indikator & 100 & 32 & 20 & 14 & 14 & 9 & 9 \\
\hline Persentase Pencapaian $(\%)$ & &
\end{tabular}

Rata-rata pencapaian hasil pengerjaan tune up sepeda motor dari semua siswa adalah 142. Setiap siswa memiliki pencapaian hasil kerja yang berbeda-beda. Persentase ketercapaian hasil kerja tune up sepeda motor untuk seluruh siswa dapat dilihat pada Tabel.

Tabel 3. Persentase Ketercapaian Hasil Kerja Tune Up Sepeda Motor

\begin{tabular}{lccccccc}
\hline \multirow{2}{*}{ Indikator } & \multicolumn{7}{c}{ Ketercapaian } \\
\cline { 2 - 9 } & $\mathrm{S}$ & $\mathrm{S} 1$ & $\mathrm{~S} 2$ & $\mathrm{~S} 3$ & $\mathrm{~S} 4$ & $\mathrm{~S} 5$ & \multicolumn{1}{c}{ S6 } \\
\hline Skor & 165 & 152 & 151 & 142 & 145 & 134 & 129 \\
\hline Persentase Pencapaian (\%) & 100 & 92.12 & 91.52 & 86.06 & 87.88 & 81.21 & 78.18 \\
\hline
\end{tabular}

\section{PEMBAHASAN}

Rata-rata waktu pengerjaan perawatan sepeda motor dari semua siswa adalah 121,58 menit dan persentase ketercapaian waktu pengerjaan untuk siswa dengan nilai tertinggi adalah $32 \%$ dan $20 \%$, nilai sedang masing-masing $14 \%$ dan siswa dengan nilai rendah mashing-masing 9\%. Waktu pengerjaan tune up sepeda motor yang dicapai oleh setiap siswa dijabarkan sebagai berikut: siswa dengan nilai tertinggi adalah 105 dan 116,5 menit, waktu pengerjaan siswa dengan nilai sedang adalah 119,5 dan 121,5 menit, sedangkan waktu pengerjaan untuk siswa dengan nilai terendah adalah 132,5 dan 134,5. Alokasi standar waktu untuk pengerjaan tune up adalah 90 menit. Tidak ada satupun siswa yang memenuhi standar untuk pengerjaan tune up sepeda motor.

Data yang didapat masih banyak indikator yang masih belum tercapai. Agar siswa dapat mencapai waktu yang standar perlu dilakukan latihan yang cukup. Bimbingan dari guru dan meningkatkan kedisiplinan serta fokus dalam bekerja. Rata- 
rata pencapaian hasil pengerjaan tune up sepeda motor dari semua siswa adalah 142 . Ketercapaian hasil pengerjaan tune up sepeda motor oleh siswa dengan nilai tertinggi adalah $92.12 \%$ dan $91.52 \%$, siswa dengan nilai sedang $86.06 \%$ dan $87.88 \%$. Sedangkan siswa dengan nilai terendah adalah $81.21 \%$ dan $78.18 \%$. Perincian pencapaian hasil kerja oleh setiap siswa adalah sebagai berikut: untuk siswa dengan nilai tertinggi mencapai 152 dan 151, siswa dengan nilai sedang 142 dan 145, sedangkan siswa dengan nilai rendah 134 dan 129. Pencapaian standar ketercapaian hasil tune up sepeda motor yang ditetapkan adalah 165. Masih banyak indikator yang masih belum tercapai. Agar siswa dapat mencapai hasil yang standar perlu dilakukan latihan yang cukup, bimbingan dari guru dan meningkatkan kedisiplinan serta fokus dalam bekerja.

\section{KESIMPULAN}

Kesimpulan penelitian ini, sebagai berikut rata-rata waktu pengerjaan perawatan sepeda motor dari semua siswa adalah 121,58 menit. Persentase ketercapaian waktu pengerjaan untuk siswa dengan nilai tertinggi adalah $32 \%$. Waktu pengerjaan tune up sepeda motor yang dicapai oleh setiap siswa dijabarkan sebagai berikut: siswa dengan nilai tertinggi adalah 105 dan 116,5 menit. Alokasi standar waktu untuk pengerjaan tune up adalah 90 menit. Data menunjukkan tidak ada satupun siswa yang memenuhi standar untuk waktu pengerjaan tune up sepeda motor. Rata-rata pencapaian hasil pengerjaan tune up sepeda motor dari semua siswa adalah 142. Pencapaian standar ketercapaian hasil tune up sepeda motor yang ditetapkan adalah 165. Dilihat dari data yang didapat tidak ada satupun siswa yang memenuhi standar untuk hasil pengerjaan tune up sepeda motor.

\section{DAFTAR PUSTAKA}

Departemen Pendidikan Nasional. (2003). Undang-Undang RI Nomor 20 Tahun 2003, Tentang Sistem Pendidikan Nasional. Jakarta: Departemen Pendidikan Nasional.

Nugraha, B. S. (2005). Modul Tune Up Sepeda Motor. Yogyakarta: Fakultas Teknik UNY.

Sumiati dan Asra. (2011). Metode Pembelajaran. Bandung: CV Wacana Prima.

Syah, M. (2013). Psikologi Pendidikan Dengan Pendekatan Baru. Bandung: PT Remaja Rosada. 